\title{
Fatigue Behaviour of Stainless Steel Used for Turbine Runners
} \author{
Negru Radu ${ }^{1, a}$, Marsavina Liviu, ${ }^{1, b}$, Muntean Sebastian ${ }^{2, c}$ and Niculai Pasca ${ }^{1, d}$ \\ 1"Politehnica" University of Timisoara, Victoriei Square 2, 300006, Timisoara, Romania \\ ${ }^{2}$ Centre of Advanced Research in Engineering Sciences, Romania Academy-Timisoara Branch, \\ Bv. Mihai Viteazu 24, 300223, Timisoara, Romania
}

aradun@mec.upt.ro, ’msvina@mec.upt.ro, cseby@acad-tim.tm.edu.ro, ${ }^{\text {d }}$ nicu_pasca@yahoo.com

Keywords: stainless steel, S-N curve, fatigue crack growth.

\begin{abstract}
The key ingredient for any turbine runners design procedure and failure analysis is the material and its mechanical and fatigue properties. Starting from this observation, a series of static and dynamic tests were performed on the $\mathrm{T} 10 \mathrm{CuNiCr} 180$ stainless steel after more than three decades of service. The fatigue tests were carried out under constant amplitude at a stress ratio of 0.1 and a frequency of $20 \mathrm{~Hz}$. In the high cycle fatigue range, the S-N median curve was plotted and the fatigue limit for $3 \cdot 10^{6}$ cycles to failure was determined at $93.35[\mathrm{MPa}]$ expressed in stress amplitude. The casting and welding defects that were observed on fracture surfaces explained this lower fatigue limit. The fatigue crack growth tests were performed on compact tension specimens and a three-parameter model was used to plot the crack length versus number of cycles curves. In addition, the material constants from Paris' law were determined. Finally, the experimental results are compared against published data for another stainless steel.
\end{abstract}

\section{Introduction}

The variable demand on the energy market and the limited energy storage capabilities require a great flexibility in hydraulic turbines operation in order to regulate the electrical grid. As a result, the hydropower units are frequently operated with a large number of start-stop cycles and over an extended range of regimes, with pressure pulsations due to unsteady hydrodynamics phenomena (e.g. rotor-stator interaction, vortex, and so on), [1]. Therefore, several failures on machine elements of the hydropower units were reported in Romania after more than three decades in service operation, [2-4]. In these conditions, the reliability and maintenance of the hydropower equipments are the main elements in order to safety operate with minimum costs, [5]. Moreover, a refurbishment strategy has to be defined based on technical and economical conditions in order to avoid catastrophic events [6]. Consequently, a considerable amount of investigations target the better understand of failure mechanisms and the appropriate material selection. The key ingredient for any design procedure or failure analysis is the material and its mechanical properties.

Starting from these observations, this paper presents key results of the experimental investigation performed in order to evaluate the fatigue behaviour of the stainless steel used for a Francis runner and operated more than 30 years in the hydropower plant. The second section presents the material and its mechanical properties obtained through static tensile tests, Charpy V-notch impact tests and Vickers hardness tests. The next section presents the experimental results and the statistical data analysis in high cycle fatigue regime. The investigation of fatigue crack growth behaviour performed on compact tension specimens is described in the fourth section. A three-parameter model for fatigue crack growth data analysis was used and the material constants from Paris' law were determined. The conclusions are drawn in the last section.

\section{Material}

The material used in these experimental studies is the Romanian T10CuNiCr180 stainless steel. According to the metallographic investigations reported in [2] the $\mathrm{T} 10 \mathrm{CuNiCr} 180$ stainless steel has a microstructure consisting of 35 [\%] ferrite, and equal proportions of martensite and austenite. The 
chemical composition was measured by energy dispersed X-ray spectrometry and is presented in Table 1.

The static and dynamic tests were performed in the "Strength of Materials Laboratory" at Politehnica University of Timisoara using a servo-hydraulic testing machine (Multipurpose Dynamic Testing System, LFV-100-HH, Walter+bai ag, Switzerland). For this testing machine the linear displacement is measured with an integrated LVDT transducer. The force is measured using a transducer with nominal load $150[\mathrm{kN}]$ within accuracy class 0.02 . The alignment fixture is fixed on the upper crosshead and provides the alignment adjustment of the load string complying with ASTM E1012-05 standard.

Table 1. Chemical composition of $\mathrm{T} 10 \mathrm{CuNiCr} 180$ stainless steel

\begin{tabular}{ccccccccc}
\hline & $\mathbf{C}$ & $\mathbf{S i}$ & $\mathbf{M n}$ & $\mathbf{C u}$ & $\mathbf{N i}$ & $\mathbf{C r}$ & $\mathbf{M o}$ & $\mathbf{T i}$ \\
& {$[\%]$} & {$[\%]$} & {$[\%]$} & {$[\%]$} & {$[\%]$} & {$[\%]$} & {$[\%]$} & {$[\%]$} \\
\hline T10CuNiCr180 & 0.07 & 0.78 & 1.87 & 1.72 & 3.82 & 18.11 & 0.15 & 0.13 \\
\hline
\end{tabular}

All the specimens were taken from a broken Francis runner blade and were prepared by electrical discharge machining. After that, the specimen's surface was grinded and polished in order to obtain a high surface quality. The geometries and dimensions for test specimens were established according to the corresponding standard requirements.

Firstly, the static behaviour was investigated through tensile tests performed under load control. The experiments were conducted according to ASTM E8 M-04, a total number of 5 specimens being tested. The axial strain was measured using a multifunctional Walter+bai MFA extensometer having a gauge length of $50[\mathrm{~mm}]$. From the plotted $\sigma-\varepsilon$ curves the Young's modulus E, yield strength $\sigma_{y}$, tensile strength $\sigma_{u}$ and elongation to fracture $A_{5}$ were determined, in Table 2 the averaged values being presented.

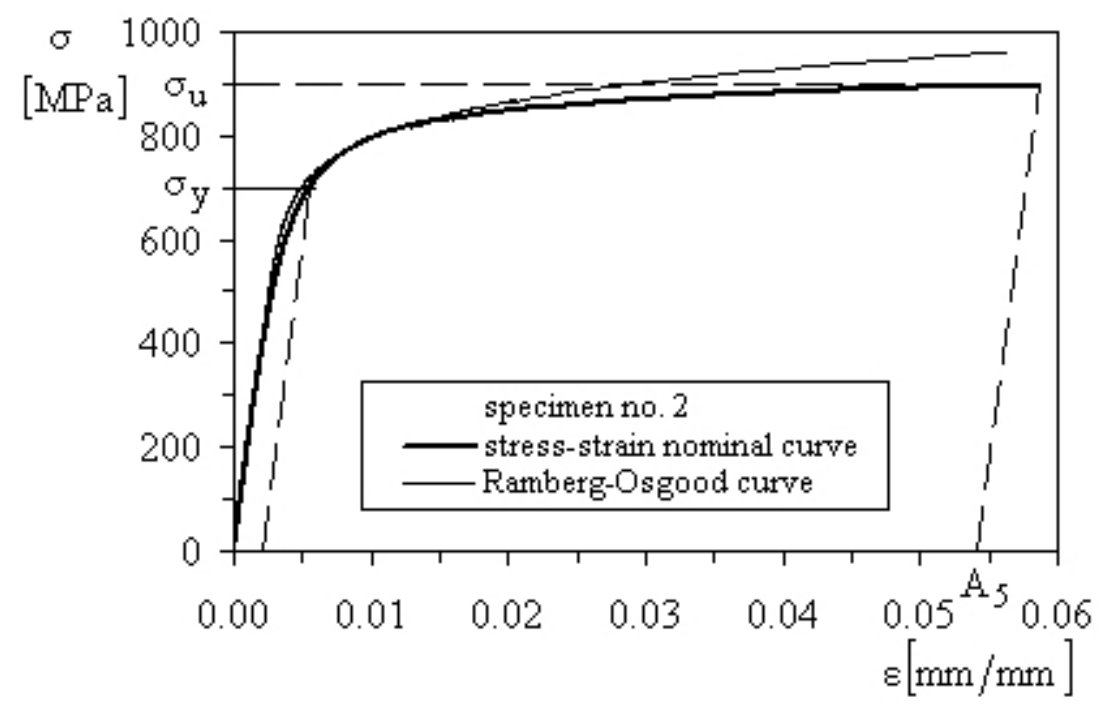

Fig. 1. Nominal and Ramberg-Osgood approximation of $\sigma-\varepsilon$ curve

For the determination of plastic deformations, the $\sigma-\varepsilon$ curve is frequently approximated using the Ramberg-Osgood law, [7]:

$$
\varepsilon_{\mathrm{t}}=\frac{\sigma_{\mathrm{t}}}{\mathrm{E}}+\left(\frac{\sigma_{\mathrm{t}}}{\mathrm{k}}\right)^{1 / \mathrm{n}},
$$

where $\sigma_{\mathrm{t}}$ is the true stress, $\varepsilon_{\mathrm{t}}$ is the true strain, $\mathrm{k}$ represents a parameter which describes the absolute stress level, and $\mathrm{n}$ is the strain hardening exponent (the averaged values for $\mathrm{k}$ and $\mathrm{n}$ are shown in Table 2). In Fig. 1 the nominal $\sigma-\varepsilon$ curve and the Ramberg-Osgood approximation are plotted for specimen no.2. 
A Zwick/Roell HIT 50P device were used for performing the Charpy V-notch impact test. As it is stated in [8], the low value of absorbed energy indicates that the T10CuNiCr180 stainless steel is likely to initiate fractures, after more than 30 years of service. Moreover, the flat appearance of the fracture surfaces indicates that the mechanism of failure was certainly brittle.

The Vickers hardness was determined using a 10 [kgf] force and the $\mathrm{HV}_{10}$ value was found to be in agreement with the results reported in [9] for JIS SCS6 stainless steel.

Table 2. Mechanical properties of T10CuNiCr180 stainless steel

\begin{tabular}{ccccccccc}
\hline & $\begin{array}{c}\mathbf{E} \\
{[\mathbf{G P a}]}\end{array}$ & $\begin{array}{c}\boldsymbol{\sigma}_{\mathbf{u}} \\
{[\mathbf{M P a}]}\end{array}$ & $\begin{array}{c}\boldsymbol{\sigma}_{\mathbf{y}} \\
{[\mathbf{M P a}]}\end{array}$ & $\begin{array}{c}\mathbf{A}_{\mathbf{5}} \\
{[\mathbf{\%}]}\end{array}$ & $\begin{array}{c}\mathbf{k} \\
{[\mathbf{M P a}]}\end{array}$ & $\begin{array}{c}\mathbf{n} \\
{[-]}\end{array}$ & $\begin{array}{c}\mathbf{C V N} \\
\text { energy [J] }\end{array}$ & $\begin{array}{c}\mathbf{H V}_{\mathbf{1 0}} \\
{[\%]}\end{array}$ \\
\hline $\mathrm{T} 10 \mathrm{CuNiCr} 180$ & 205.68 & 697.30 & 891.44 & 4.71 & 1240 & 0.085 & 4.85 & 320 \\
\hline
\end{tabular}

\section{Stress-based fatigue tests}

Experimental results. In order to estimate statistically the full S-N curve, including both finite and infinite fatigue life ranges, the method proposed in [10] was employed. This method requires a reasonable sample size: 8 specimens are used to determine the finite fatigue life range and other 6 specimens are used to establish the fatigue limit.

The constant amplitude axial fatigue tests were carried out under load control, in an open environment at room temperature complying with ASTM E466-02. Using a sinusoidal wave, the flat specimens were cyclically loaded at load ratio of $\mathrm{R}=0.1$ at a frequency of 20 [Hz].

Table 3. Results of stress-based fatigue experiments

\begin{tabular}{cccccccc}
\hline Specimens & $\begin{array}{c}\sigma_{\max } / \boldsymbol{\sigma}_{\mathbf{u}} \\
{[-]}\end{array}$ & $\begin{array}{c}\sigma_{\max } \\
{[\mathbf{M P a}]}\end{array}$ & $\begin{array}{c}\boldsymbol{\sigma}_{\min } \\
{[\mathbf{M P a}]}\end{array}$ & $\begin{array}{c}\boldsymbol{\sigma}_{\mathbf{a}} \\
{[\mathbf{M P a}]}\end{array}$ & $\begin{array}{c}\Delta \boldsymbol{\sigma} \\
{[\mathbf{M P a}]}\end{array}$ & $\begin{array}{c}\mathbf{N}_{\mathbf{f}} \\
{[\mathbf{c y c l e s}]}\end{array}$ & Observations \\
\hline 1 & 0.50 & 450.00 & 45.00 & 202.50 & 405.00 & 85100 & \\
\hline 2 & 0.50 & 450.00 & 45.00 & 202.50 & 405.00 & 102100 & \\
\hline 3 & 0.40 & 360.00 & 36.00 & 162.00 & 324.00 & 162940 & \\
\hline 4 & 0.40 & 360.00 & 36.00 & 162.00 & 324.00 & 138130 & \\
\hline 5 & 0.30 & 270.00 & 27.00 & 121.50 & 243.00 & 826640 & \\
\hline 6 & 0.30 & 270.00 & 27.00 & 121.50 & 243.00 & 389240 & \\
\hline 7 & 0.28 & 254.88 & 25.48 & 114.69 & 229.39 & 892220 & \\
\hline 8 & 0.28 & 254.88 & 25.48 & 114.69 & 229.39 & 570960 & \\
\hline 9 & 0.25 & 225.00 & 22.50 & 101.25 & 202.50 & 1072320 & \\
\hline 10 & 0.23 & 209.97 & 20.99 & 94.48 & 188.97 & 1340260 & \\
\hline 11 & 0.23 & 209.97 & 20.99 & 94.48 & 188.97 & 1966720 & \\
\hline 12 & 0.23 & 209.97 & 20.99 & 94.48 & 188.97 & 3000070 & run-out \\
\hline 13 & 0.21 & 194.99 & 19.49 & 87.72 & 175.44 & 3000150 & run-out \\
\hline 14 & 0.21 & 194.99 & 19.49 & 87.72 & 175.44 & 3400030 & run-out \\
\hline
\end{tabular}

In the finite fatigue life region two specimens were tested until failure for each of 4 different stress levels $\sigma_{\max } / \sigma_{u}(0.50,0.40,0.30,0.28)$. In the infinite fatigue life region the tests were performed following the modified staircase method (or up and down method) with the stress step established at $6.76\left[\mathrm{MPa}\right.$ ]. For the specimens which didn't fail in $3 \cdot 10^{6}$ [cycles] the experiments were stopped and the corresponding results were considered as run-out. The stress-based fatigue 
experimental results are shown in table 3, and are plotted Fig. 2 in log-log coordinates, where the xcoordinate is expressed in terms of reversals $2 \mathrm{~N}_{\mathrm{f}}$ to failure and the y-coordinate is expressed in terms of applied stress amplitude $\sigma_{\mathrm{a}}$.

S-N curve in finite life range. Analysis of fatigue data assumes that the $\mathrm{S}-\mathrm{N}$ curve can be represented as an inclined straight line (i.e. the slope is constant) in the finite life region in log-log coordinates. In the stress-based approach, the Basquin relation is the most used equation to represent the S-N curve:

$$
\sigma_{\mathrm{a}}=\sigma_{\mathrm{f}}^{\prime} \times\left(2 \mathrm{~N}_{\mathrm{f}}\right)^{\mathrm{b}}
$$

where $b$ is the fatigue strength exponent and $\sigma_{f}$ is the fatigue strength coefficient. The statistical analysis assumes also that the resulted fatigue life $2 \mathrm{~N}_{\mathrm{f}}$ follows the lognormal distribution for an amplitude stress level $\sigma_{\mathrm{a}}$, [11]. From Eq. (2) by taking logarithms for both sides and using the leastsquares method, the following relation was obtained for S-N curve plotted in Fig. 2 with a reliability of $50 \%$ :

$$
\sigma_{\mathrm{a}}=5112 \times\left(2 \mathrm{~N}_{\mathrm{f}}\right)^{-0.2689} \text {. }
$$

In addition, two statistical fatigue properties were derived:

$$
\mathrm{s}=0.1321, \quad \mathrm{C}_{\sigma}=\sqrt{10^{\mathrm{b}^{2} \mathrm{~s}^{2}}-1}=0.0540,
$$

where $\mathrm{s}$ is the standard sample deviation of $\log \left(2 \mathrm{~N}_{\mathrm{f}}\right)$ estimates on $\log \left(\sigma_{\mathrm{a}}\right)$, and $\mathrm{C}_{\sigma}$ is the coefficient of variation of $\sigma_{\mathrm{f}}$.

Taking into account the statistical nature of fatigue, in the finite life range the lower bound of the S-N curve was determined using the approximate Owen one-side tolerance limit approach presented in [12]. In fact, the lower bound in log-log coordinates is obtained by horizontally shifting to the left the median S-N curve with a quantity $\mathrm{s} \times \mathrm{K}_{\text {owen }}$, where the values of $\mathrm{K}_{\text {owen }}$ factor are tabled in [13]. For the sample size $\mathrm{n}_{\mathrm{S}}=8$, a 95 [\%] probability of survival and a 95 [\%] confidence level yields to $\mathrm{K}_{\text {owen }}=3.534$. The lower bound obtained for S-N curve is plotted in Fig. 2:

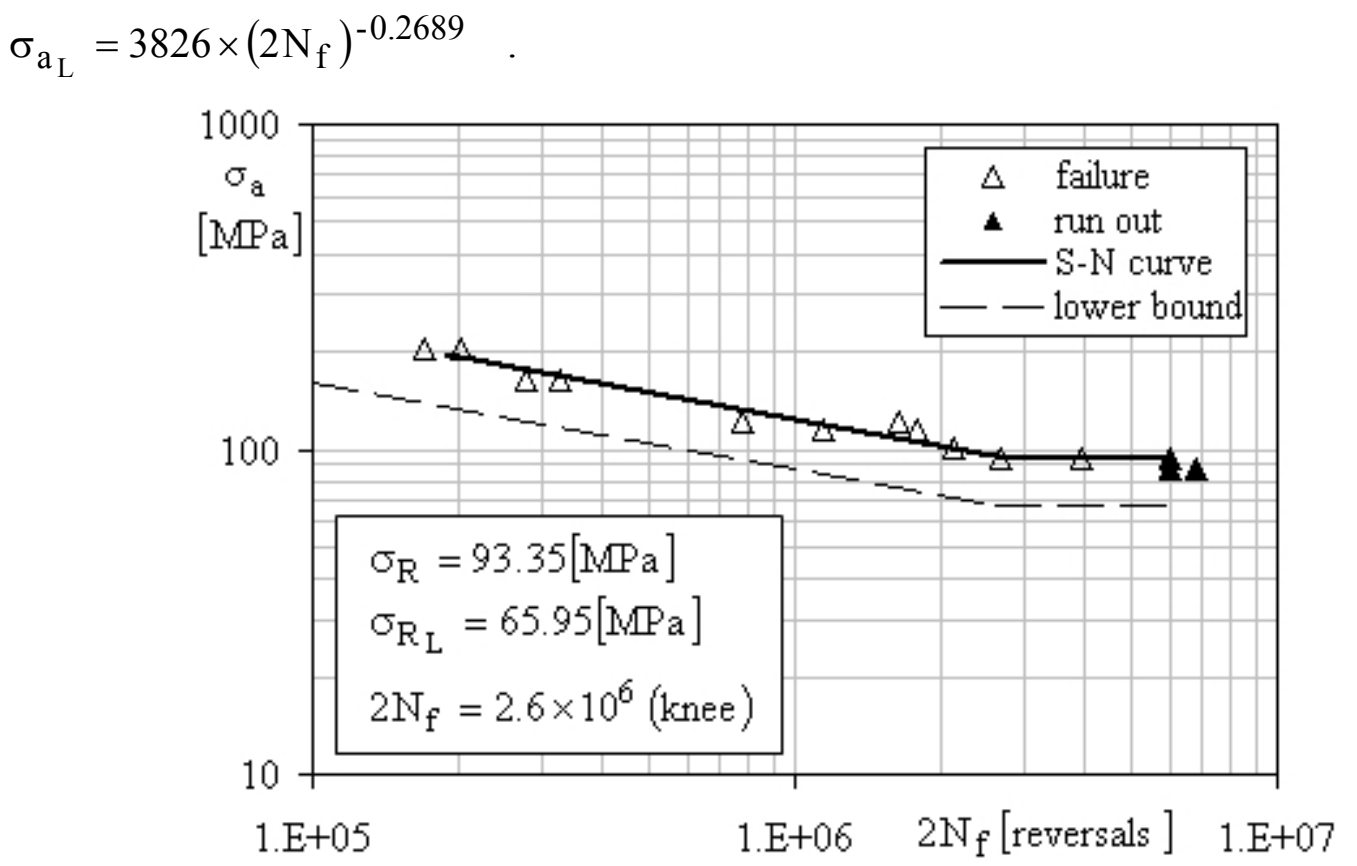

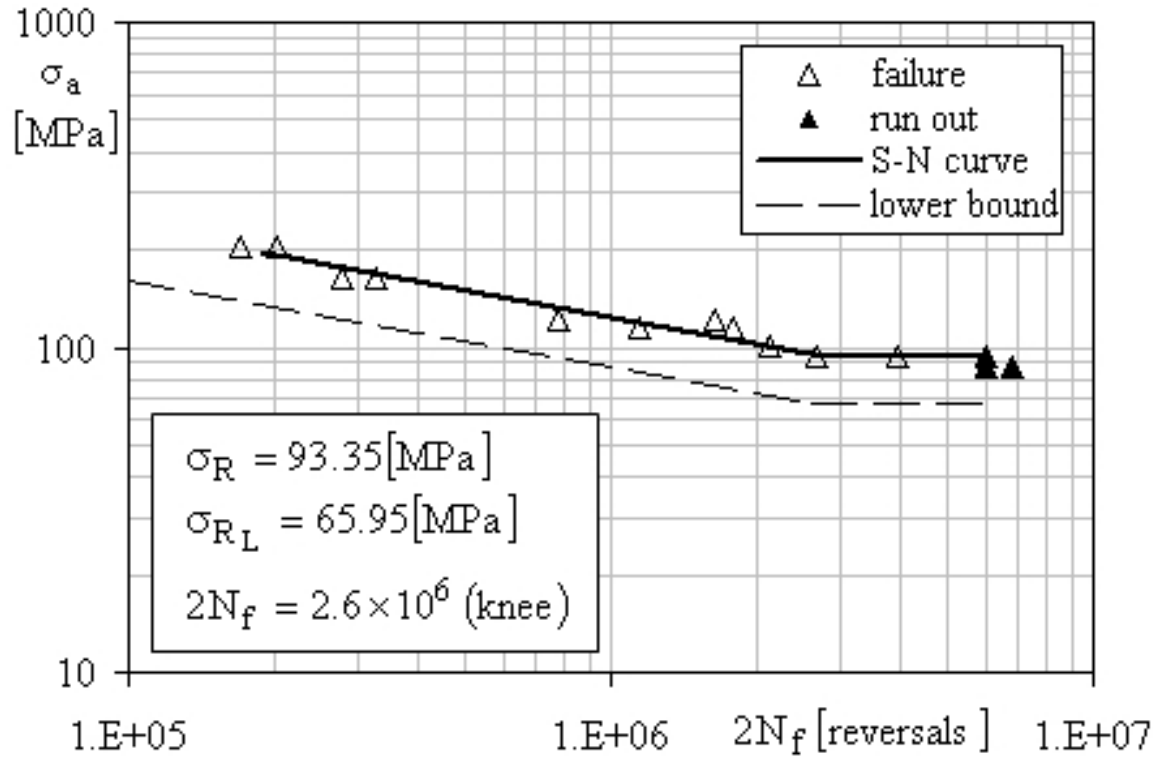

Fig. 2. S-N curve for $\mathrm{T} 10 \mathrm{CuNiCr} 180$ stainless steel 
Fatigue limit estimation. The staircase method is the most used fatigue limit test technique and was adopted by several standards, [11]. The experiments were conducted by decreasing or increasing the stress level with a fixed step $d=6.76[\mathrm{MPa}]$, depending on the previous test result (failure or run out). For the results shown in Table 3 (specimens $9 \div 14$ ), the staircase method generates the sequence plotted in Fig. 3. Considering the failure event in the statistical analysis, the data reduction technique proposed in [14] is used for fatigue limit estimation. As it is presented in Fig. 3, the stress levels $\sigma_{i}(i=0 \div 2)$ are equally spaced by the chosen increment $\mathrm{d}$. The failure events at the stress level $\sigma_{i}$ are denoted by $n_{i}\left(n_{0}=0, n_{1}=2, n_{2}=1\right)$. Thus, the fatigue limit in terms of stress amplitude results as the mean value calculated using the equation:

$$
\sigma_{\mathrm{R}}=\sigma_{0}+\mathrm{d}\left(\sum \mathrm{in}_{\mathrm{i}} / \Sigma \mathrm{n}_{\mathrm{i}}-0.5\right)=93.35[\mathrm{MPa}],
$$

with the standard deviation:

$$
\mathrm{s}_{\sigma}=0.53 \mathrm{~d}=3.58[\mathrm{MPa}] \text {, }
$$

for the case $\left(\sum \mathrm{i}^{2} \mathrm{n}_{\mathrm{i}} \sum \mathrm{n}_{\mathrm{i}}-\left(\sum \mathrm{in}_{\mathrm{i}}\right)^{2}\right) /\left(\sum \mathrm{n}_{\mathrm{i}}\right)^{2}<0.3$. Assuming a normal distribution the lower bound in the infinite range is determined using the expression:

$$
\sigma_{\mathrm{R}_{\mathrm{L}}}=\sigma_{\mathrm{R}}-\mathrm{K} \times \mathrm{s}_{\sigma}=65.95[\mathrm{MPa}] \text {, }
$$

where $K=7.655$ for $95[\%]$ probability of survival, 95 [\%] confidence level, and number of failure events $\mathrm{n}=3$.

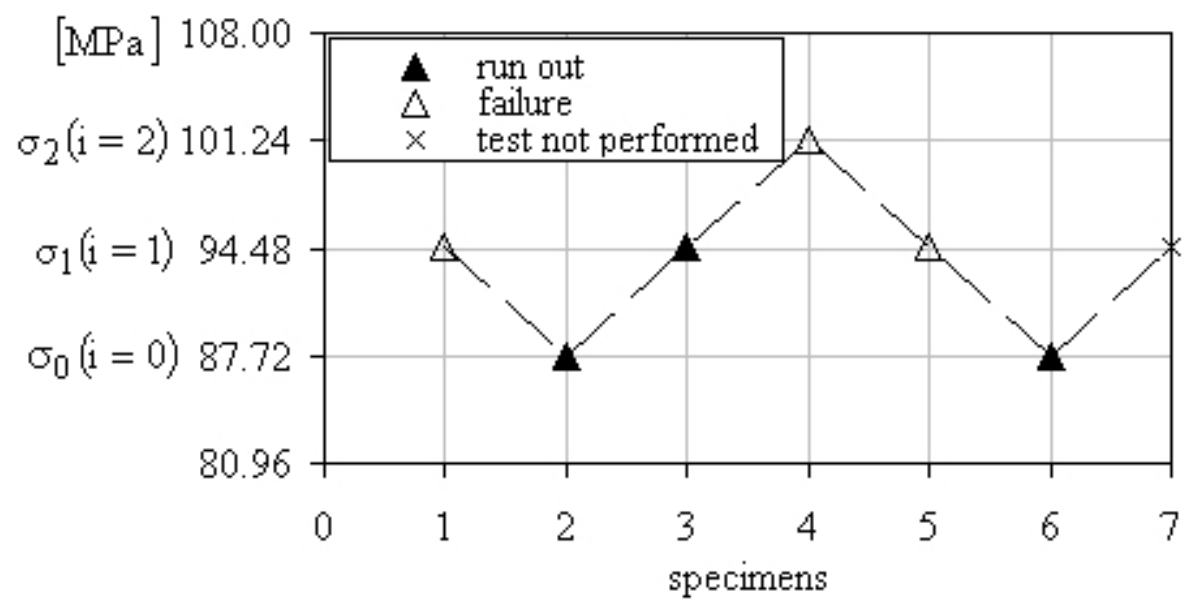

Fig. 3. The staircase fatigue data

Consequently, in Fig. 2 the knee point of the S-N curve corresponds to the $2 \mathrm{~N}_{\mathrm{f}}=2.6 \times 10^{6}$ [reversals].

\section{Fatigue crack growth (FCG) tests}

Experiments. The constant-force amplitude FCG tests were performed under load control in tension-tension cycling of load ratio $\mathrm{R}=0.1$ and $20[\mathrm{~Hz}]$ frequency, a total number of 3 compact tension (CT) specimens being tested. Their reference dimensions were $\mathrm{W}=50[\mathrm{~mm}]$ (width) and $\mathrm{B}=10[\mathrm{~mm}]$ (thickness). According to ASTM E647-00, the fatigue precracking was conducted employing the stepped-down technique so that the final maximum stress intensity factor $\mathrm{K}_{\max }$ during precracking did not exceed the corresponding $\mathrm{K}_{\max }$ for FCG tests. A clip-on extensometer having a gauge length of $10[\mathrm{~mm}]$ was used to measure the growing crack, employing the compliance technique:

$$
\mathrm{a}=\mathrm{W} \times\left(\mathrm{C}_{0}+\mathrm{C}_{1} \mathrm{u}_{\mathrm{x}}+\mathrm{C}_{2} \mathrm{u}_{\mathrm{x}}^{2}+\mathrm{C}_{3} \mathrm{u}_{\mathrm{x}}^{3}+\mathrm{C}_{4} \mathrm{u}_{\mathrm{x}}^{4}+\mathrm{C}_{5} \mathrm{u}_{\mathrm{x}}^{5}\right)
$$


where $u_{x}=\left[(E v B / F)^{0.5}+1\right]^{-1}$, a is the crack length, $v$ is the displacement between measurements points, $\mathrm{F}$ is the applied load, and the coefficients $\mathrm{C}_{\mathrm{i}}$ are given by ASTM E647-00. Moreover, for the $\mathrm{CT}$ specimen the stress intensity factor range $\Delta \mathrm{K}$ corresponding to a given crack length is calculated as follows:

$$
\Delta \mathrm{K}=\frac{\Delta \mathrm{F}}{\mathrm{B} \sqrt{\mathrm{W}}} \frac{(2+\alpha)}{(1-\alpha)^{3 / 2}}\left(0.866+4.64 \alpha-13.32 \alpha^{2}+14.72 \alpha^{3}-5.6 \alpha^{4}\right),
$$

where $\alpha=\mathrm{a} / \mathrm{W}$ represents the normalized crack size and $\Delta \mathrm{F}=\mathrm{F}_{\max }-\mathrm{F}_{\min }=9[\mathrm{kN}]$ is the applied load range. The crack length versus number of cycles curve a-N derived experimentally is shown in Fig. 4 for CT specimen 3. As can be seen a scatter of FCG data is observed especially at low crack length. To approximate the a-N curve, in order to avoid the scatter of the experimental data the 3parameter model proposed in [15] was employed:

$$
\mathrm{a}=\frac{\mathrm{a}_{0}+\gamma}{\left[1-\frac{(\alpha \mathrm{N})}{\mathrm{N}_{\mathrm{f}}}\right]^{\beta}}
$$

In Eq. (10) the parameters $\alpha, \beta$, and $\gamma$ are determined according to non-linear least square method, while $\mathrm{a}_{0}$ represents the initial crack length, $\mathrm{N}_{\mathrm{f}}$ is the number of cycles to failure, and a is the crack length at a given number of cycles N. For the presented CT specimen the values of these parameters are: $\alpha=0.88653, \beta=0.53187, \gamma=-0.7895$, with $\mathrm{a}_{0}=10.7036$ [mm] and $\mathrm{N}_{\mathrm{f}}=242003$ [cycles] (Fig. 4). Thus, the fatigue crack growth rate da/dN can be directly evaluated through the previous expression (11).

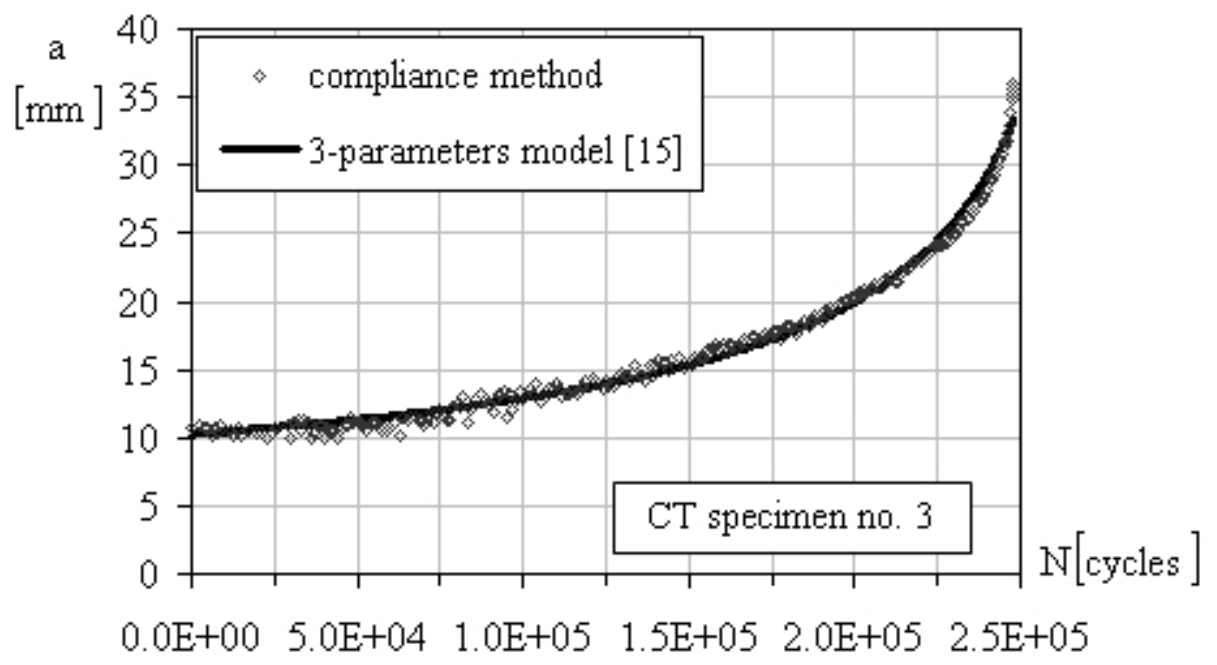

Fig. 4. Crack length vs. number of cycles curve (CT specimen no. 3)

FCG data analysis. For the FCG the first and commonly used fracture mechanics based model was proposed in the early '60s [16]. The empirical derived law, known as Paris' law:

$$
\frac{\mathrm{da}}{\mathrm{dN}}=\mathrm{C}(\Delta \mathrm{K})^{\mathrm{m}}
$$

represents a straight line in log-log coordinates, where da/dN is the FCG rate, $\mathrm{C}$ and $\mathrm{m}$ are material constants, and $\mathrm{N}$ the number of cycles at a given crack length. Other empirical FCG rate laws were derived as a refinement of Eq. (10) by taking into account the effect of stress ratio [17] or the effect of retardation due to the plastic zone formation at the crack tip [18]. To obtain the values of $\mathrm{C}$ and $\mathrm{m}$ the least square method is usually used to fit the FCG data. 
Using the 3-parameters model for the crack length curve, the constants from Eq. (11) were determined in $2 \cdot 10^{-5} \div 10^{-4}$ [mm/cycle] FCG rate range, according to the recommendations stipulated by ASTM E647-00. For the CT specimen no. 3 the da/dN versus $\Delta \mathrm{K}$ curve is plotted in Fig. 5 . The material constants determined for 0.1 stress ratio are $\mathrm{C}=2 \times 10^{-10}$ and $\mathrm{m}=4.11$. The averaged values of these constants are shown in Table 4 for comparison against the results reported in [9] for JIS SCS6 stainless steel.

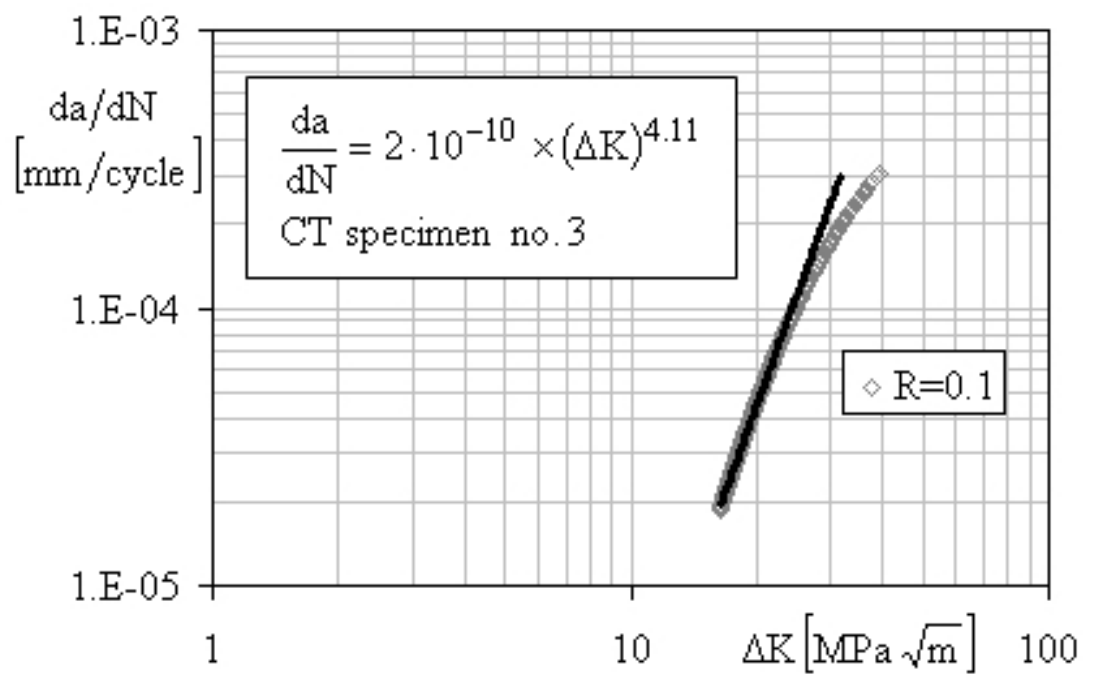

Fig. 5. Fatigue crack growth rate as a function of $\Delta K$

\section{Conclusions}

This paper summarized the fatigue experimental data obtained in order to characterize the fatigue behaviour of $\mathrm{T} 10 \mathrm{CuNiCr} 180$ stainless steel after more than 30 years in service. All the fatigue experiments were conducted at constant amplitude and load ratio of $\mathrm{R}=0.1$.

In the high cycle fatigue regime the median S-N curve and the lower bound (for 95 [\%] probability of survival and a 95 [\%] confidence) were plotted based on a statistical analysis of the experimental data. The material constants from Paris' equation were also determined using a 3parameter model to approximate the crack length vs. number of cycles curve.

The main properties listed in Table 4 are compared against the values reported in [9] for the JIS SCS6 stainless steel after more than 20 years in service. As it can be seen, the static mechanical properties (yield strength and tensile strength) are comparable, while small differences are observed for the Paris' law material constants. Even if the fatigue limit for JIS SCS6 stainless steel was determined for the case $\mathrm{R}=-1$, the reported value in [9] is approximately three times larger than the fatigue limit for $\mathrm{T} 10 \mathrm{CuNiCr} 180$ stainless steel. The casting and welding defects that were observed on fracture surfaces explained this lower fatigue limit.

Table 4. Mechanical properties of T10CuNiCr180 stainless steel

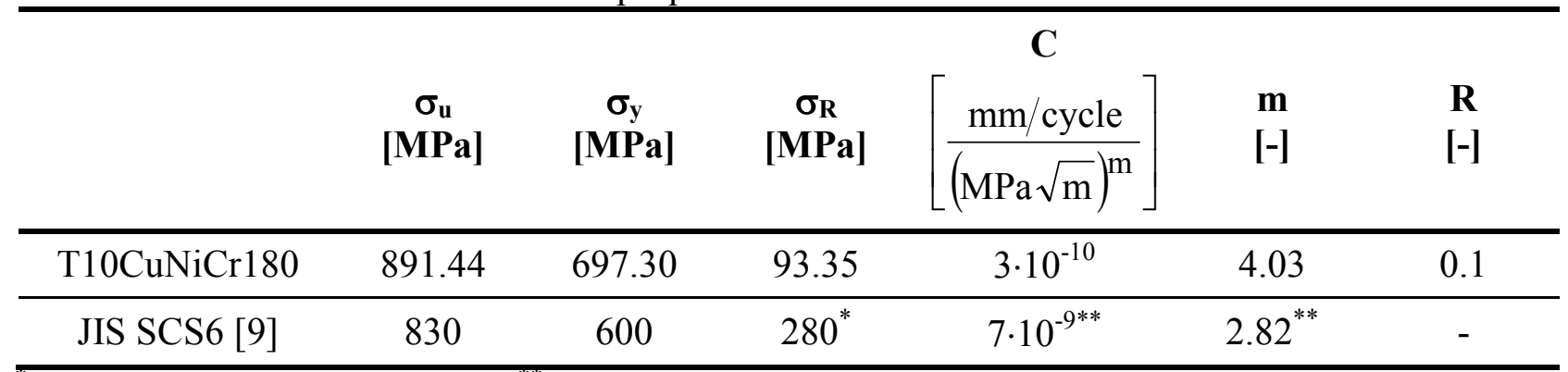

"determined at stress ratio $\mathrm{R}=-1$; $\quad$ determined at stress ratio $\mathrm{R}=0.05$. 


\section{Acknowledgments}

This paper was supported by the project "Development and support for multidisciplinary postdoctoral programmes in major technical areas of national strategy of Research-DevelopmentInnovation" 4D-POSTDOC, Contract No. POSDRU/89/1.5/S/52603, project co-funded by the European Social Fund through Sectorial Operational Programme Human Resources Development 2007-2013.

\section{References}

[1] A. Baya, S. Muntean, V.C. Campian, A. Cuzmos, M. Diaconescu, M. Balan, Experimental investigations of the unsteady flow in a Francis turbine draft tube cone, IOP Conf. Ser.: Earth Environ. Sci. 12 (2010) 012007.

[2] D. Frunzaverde, S. Muntean, G. Marginean, V. Campian, L. Marsavina, R. Terzi, V. Serban, Failure analysis of a Francis turbine runner, IOP Conf. Ser.: Earth Environ. Sci. 12 (2010) 012115.

[3] D. Chiorean, I. Rogoz, I. Poienariu, Technical problems arising from the operation of hydraulic turbines at SHC, Timisoara Academic Days, XI Edition, Timisoara, (2009) 1-8.

[4] N. Pasca, L. Marsavina, S. Muntean, R. Negru: submitted to Engineering Failure Analysis (2013).

[5] H. Brekke, Performance and safety of hydraulic turbines, IOP Conf. Ser.: Earth Environ. Sci. 12 (2010) 012061.

[6] S. Muntean, I. Ninaci, R. Susan-Resiga, A. Baya, I. Anton, Numerical analysis of the flow in the old Francis runner in order to define the refurbishment strategy, UPB Scientific Bulletin Series D: Mechanical Engineering 72 (2010) 117-124.

[7] J. Roesler, H. Harders, M. Baeker, Mechanical Behaviour of Engineering Materials, SpringerVerlag, Berlin, 2007.

[8] ASM Handbook, vol. 8, Mechanical Testing and Evaluation, ASM International, Materials Park, 2000.

[9] N. Natsume, Y. Hayashi, H. Akebono, M. Kato, A. Sugeta, Fatigue properties and crack propagation behavior of stainless cast steel for turbine runner of hydraulic power generation, J. Proc. Eng. 2 (2010) 1273-1281.

[10] H. Nakazawa, S. Kodama, Statistical fatigue testing method with 14 specimens - JSME standard method for determination of $S-N$ curves, in: T. Tanaka, S. Nishijima, M. Ichikawa (Eds.), Statistical Research on Fatigue and Fracture (Current Japanese Materials Research, vol. 2), Elsevier Applied Science Publishers Ltd., Essex, England, 1987, pp. 59-69.

[11] Y.L. Lee, J. Pan, R.B. Hathaway, M.E. Barkey, Fatigue Testing and Analysis (Theory and Practice), Elsevier Butterworth-Heinemann, Burlington, 2005.

[12] C.L. Shen, P.H. Wirshing, G.T. Cashman, Design curve to characterize fatigue strength, J. Eng. Mater.-T. ASME 118 (1996) 535-541.

[13] C.R. Williams, Y. Lee, J.T. Rilly, A practical method for statistical analysis of strain-life fatigue data, Int. J. Fatigue 25 (2003) 427-436.

[14] W.J. Dixon, A.M. Mood, A method for obtaining and analyzing sensitivity data, J. Am. Stat. Assoc. 43 (1948) 109-126.

[15] A. De Iorio, M. Grasso, F. Penta, G.P. Pucillo, A three-parameter model fatigue crack growth data analysis, Frattura ed Integrita Strutturale 21 (2012) 21-29.

[16] P.C. Paris, F. Erdogan, A critical analysis of crack propagation laws, J. Basic Eng.-T. ASME 85 (1963) 528-534.

[17] K. Walker, The effects of stress ratio during crack propagation and fatigue for 2024-T3 and 7075-T6 aluminum, in: Effects of Environment and Complex Load History for Fatigue Life, ASTM STP 462, Philadelphia, 1970, pp. 1-14.

[18] O. Wheeler, Spectrum loading and crack growth, J. Eng. Mater.-T. ASME 94 (1972) 181-186. 